\title{
The association between bone mineral density and postoperative drainage volume following cruciate-substituting primary total knee arthroplasty: a cross-sectional study
}

Yuthasak Peerakul, Jirapong Leeyaphan * [D and Karn Rojjananukulpong

\begin{abstract}
Background: The prevalence of osteoporosis in patients who undergo a primary total knee arthroplasty (TKA) is increasing. Low bone mineral density (BMD) is related to unfavorable outcomes following TKA such as migration of uncemented tibial components. Postoperative blood loss in TKA is an important complication. Non-modifying predicting factors for postoperative blood loss in patients undergoing primary TKA need further elucidation. Studies on the association between BMD and blood loss after TKA are limited. We aimed to demonstrate the relationship between BMD and postoperative drainage volume following primary TKA.

Methods: A cross-sectional study was conducted between January 2014 and August 2020. A total of 119 primary varus osteoarthritis knees with BMD results were included in the study. Patients with secondary causes of osteoporosis were excluded.

Results: The median postoperative drainage volume of participants in the normal total hip BMD group and the normal trochanter BMD group was higher than that of patients in the low total hip BMD group and the low trochanter BMD group (285.0 ml vs $230.0 \mathrm{ml}, P=0.003 ; 282.5 \mathrm{ml}$ vs $240.0 \mathrm{ml}, P=0.013$, respectively). Multivariate regression analyses showed that operative time, spinal anesthesia, and normal total hip BMD status were significant predictive factors associated with increased postoperative drainage volume $(P=0.014,0.022$, and 0.013 ,

respectively). No association was identified between the lumbar spine BMD status and postoperative drainage volume.

Conclusions: The relationship between BMD and postoperative blood loss in primary TKA was identified in this study. Normal total hip BMD was found to be associated with an increased postoperative drainage volume after primary TKA compared with low BMD.
\end{abstract}

Keywords: Total knee arthroplasty, Bone mineral density, Blood loss, Factor

\footnotetext{
*Correspondence: lekortho@gmail.com

Bamrasnaradura Infectious Diseases Institute, Department of Disease Control, Ministry of Public health, 38 Talat Khwan, Mueang, Nonthaburi 11000,

Thailand
}

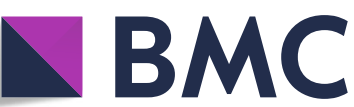

Part of Springer Nature (c) The Author(s). 2021 Open Access This article is licensed under a Creative Commons Attribution 4.0 International License, which permits use, sharing, adaptation, distribution and reproduction in any medium or format, as long as you give appropriate credit to the original author(s) and the source, provide a link to the Creative Commons licence, and indicate if changes were made. The images or other third party material in this article are included in the article's Creative Commons licence, unless indicated otherwise in a credit line to the material. If material is not included in the article's Creative Commons licence and your intended use is not permitted by statutory regulation or exceeds the permitted use, you will need to obtain permission directly from the copyright holder. To view a copy of this licence, visit http://creativecommons.org/licenses/by/4.0/. The Creative Commons Public Domain Dedication waiver (http://creativecommons.org/publicdomain/zero/1.0/) applies to the data made available in this article, unless otherwise stated in a credit line to the data. 


\section{Background}

Blood loss following total knee arthroplasty (TKA) is a common concerning postoperative complication. The type of anesthesia used [1], type of surgery, operative time, body mass index $(\mathrm{BMI})<27 \mathrm{~kg} / \mathrm{m}^{2}$ [2], prosthesis design, and postoperative anticoagulation drugs given [3] were found to be predictive of postoperative blood loss after TKA. Despite the potential for some influencing factors to be reduced in the preoperative period, there are still many predisposing factors that cannot be preoperatively modified, such as older age, sex, hypertension, the presence of rheumatoid arthritis, and an American Society of Anesthesiologists (ASA) score $>3$ [2]. Thus, many medication and methods have been investigated to reduce postoperative blood loss and blood transfusions, including tranexamic acid [4-7], computerassisted surgery [8-10], closed suction drainage [11, 12], no drainage [13], fibrin sealants [14], intramedullary femoral canal sealing [15], compression dressings [12], and a postoperative high-flexion knee position [16].

Osteoporosis is increasingly being found in patients who have undergone a primary TKA [17]. A previous study reported a prevalence of osteoporosis of $50.0 \%$ in patients awaiting TKA [18]. A low bone mineral density (BMD) was reported to be associated with unfavorable outcomes following TKA, such as the migration of uncemented tibial components [19]. The association between BMD and the volume of blood loss is controversial. A recent study showed an association between BMD and perioperative blood loss during mini-invasive posterior spinal fusion surgery. The patients who had a low lumbar spine BMD tended to have more perioperative blood loss than those with a normal BMD [20]. However, one study demonstrated no difference in the postoperative drainage volume after TKA in patients with rheumatoid arthritis, which is an osteoporosis risk factor [21], compared with normal cases with primary osteoarthritis [22]. An extensive literature review identified no previous reports on the relationship between BMD and postoperative blood loss in patients with primary TKA. This study aimed to clarify the association between BMD and the postoperative drainage volume following primary TKA. Risk factors for postoperative drainage volume were also identified and analyzed.

\section{Methods}

\section{Study population}

This cross-sectional study enrolled participants diagnosed with varus knee osteoarthritis who underwent a primary TKA with a single surgeon (YP) from January 2014 to August 2020. Participants who were diagnosed with chronic liver disease or chronic kidney disease were excluded. In addition, participants who lacked BMD results were also excluded. The study protocol was approved by the Institutional Review Board (S059h/63_ ExPD).

\section{Data collection}

Data on age, sex, underlying hypertension, BMI, anesthesia, ASA score, preoperative hemoglobin content, preoperative platelet count, operative time, 24-h postoperative mean arterial pressure (MAP), 24-h postoperative blood loss drainage volume [23], BMD, and blood transfusions were collected from medical records and included in the analysis.

Dual-energy X-ray absorptiometry (DXA) was performed at two sites: the lumbar spine (L1-L4) and the hip (femoral neck, trochanter, and total hip). All participants were assessed using the same DXA machine (Discovery Wi, Hologic, Marlborough, MA, USA). The T-score interpretation used Asian matched values. The DXA results were interpreted according to the World Health Organization criteria. T-scores of $\leq-2.5$ standard deviations (SD) below the reference mean were categorized as indicative of osteoporosis, T-scores between -1.0 and -2.5 SD as osteopenia, and T-scores $\geq-1.0$ $\mathrm{SD}$ as normal. In this study, patients with T-scores <1.0 SD were categorized as having a low BMD, while those with $\mathrm{T}$-scores $\geq-1.0 \mathrm{SD}$ were labeled as having a normal BMD.

\section{Surgical technique and postoperative management}

All TKAs were performed by a single surgeon to reduce the surgical technique bias. Patients were instructed to stop antiplatelet drugs 7 days before surgery. A tourniquet with a pressure of $300 \mathrm{mmHg}$ was used in all cases. A full-time tourniquet was used in all TKAs. The surgeries were performed after positioning. The lower extremity was prepared and draped using a standard method. The limb was elevated and exsanguinated with an elastic bandage. A straight midline skin incision was made, starting from $5 \mathrm{~cm}$ proximal to the superior pole of the patella and continuing to the medial side of the tibial tuberosity. A medial parapatellar arthrotomy was made, and then the medial soft tissue was released subperiosteally from the proximal medial part of the tibia to the posteromedial corner of the tibia. The patella was then everted after releasing the patellofemoral ligament. The anterior and posterior cruciate ligaments were released. The medial and lateral menisci were excised, and then the proximal portion of the tibia was resected at $90^{\circ}$ to its long axis with an intramedullary tibial guide. The distal femur was resected at $5^{\circ}$ valgus with an intramedullary femoral guide. The selective patella was then prepared for resurfacing. Anterior, posterior, chamfer, and box cuts were made. The trial components were placed to test the knee for stability and for adequate patellar tracking. The knee was irrigated with $1000 \mathrm{ml}$ of 
normal saline, and the bone was dried. There was no femoral bone plug to close femoral guide hole. The components (New Wave ${ }^{\mathrm{Tw}}$, Groupe Lépine, Genay, France) were cemented into place. Two grams of tranexamic acid was administered directly into the joint space. The drain was placed, and then the quadriceps tendon and joint capsule were repaired with an interrupted absorbable suture (number 1). There was no period of releasing the tourniquet for bleeding control. The skin was closed with absorbable subcuticular running sutures (number $3 / 0$ ). The knee was dressed in gauze without a bandage. The tourniquet was deflated, and then the drain was released. All patients received patient-controlled analgesia for $48 \mathrm{~h}$ without postoperative deep vein thrombosis prophylaxis. Because of the low prevalence of fatal pulmonary embolism after TKA [24] and the risk of bleeding, postoperative thromboprophylaxis was not used in this study. The drain was removed at $24-48 \mathrm{~h}$ postoperation.

\section{Statistical analysis}

A sample size calculation was performed by using G*Power 3.1 software (University of Dusseldorf, Dusseldorf, Germany) [25], which determined that a minimum of 118 participants was required with an effect size of 0.15 to achieve a statistical power $\geq 80$ at $P$-value $\alpha$ levels of $\leq 0.05$ and for 10 predictors. Descriptive analyses such as mean values with SDs, medians with the $25^{\text {th }}-75^{\text {th }}$ percentile ranges, or counts were performed. Independent sample $t$ tests were used to compare means of normally distributed data, and the Mann-Whitney $U$ test was used for non-normally distributed continuous variables. Pearson's correlation was used in the analyses. A univariate regression analysis was performed to estimate the relationships among variables and the postoperative drainage volume. In terms of qualitative variables, for sex, male was set as "1" and female was set as "0". For hypertension, yes was set as "1" and no was set as " 0 ". For anesthesia, spinal anesthesia was set as "1" and general anesthesia was set as "0". For BMD status, low was set as "1" and normal was set as "0". The variables with $P$ values of less than 0.25 in the univariate regression analysis or other variables of known clinical relevance were included for further multivariate regression analysis [26]. All data were analyzed using the Statistical Package for the Social Sciences for Windows 26.0 (Armonk, NY, USA). A $P$ value of $<0.05$ was considered statistically significant.

\section{Results}

Initially, 405 participants were to be included in the study, but 286 were excluded because of a lack of BMD results. The remaining 119 participants were included in the present study (Fig. 1). The clinical characteristics of the study population are shown in Table 1 . The median postoperative drainage volume of participants in the normal total hip BMD group and the normal trochanter BMD group was higher than that in the low total hip BMD group and the low trochanter BMD group $(P=$ $0.003, P=0.013$, respectively) (Table 2 , Fig. 2 ). The total hip T-score was analyzed and was found to have significant correlation with the postoperative drainage volume $(P=0.05)$.

The univariate regression analysis showed significant associations of the operative time, trochanter BMD status, and total hip BMD status with the postoperative drainage volume (all $P<0.05)$ (Table 3$)$. No relationships were identified between the postoperative drainage volume and femoral neck BMD status or lumbar spine BMD status.

A multivariate regression analysis was used to correct for operative time, trochanter BMD status, and total hip BMD status, which were identified as significant independent factors in the univariate regression analysis. Age, sex, BMI, hypertension, and anesthesia were analyzed in the model because of their clinical relevance to postoperative blood loss. Femoral neck BMD status, trochanter BMD status, and total hip BMD status were analyzed in a separate model because of multicollinearity problems. The multivariate analysis using total hip BMD

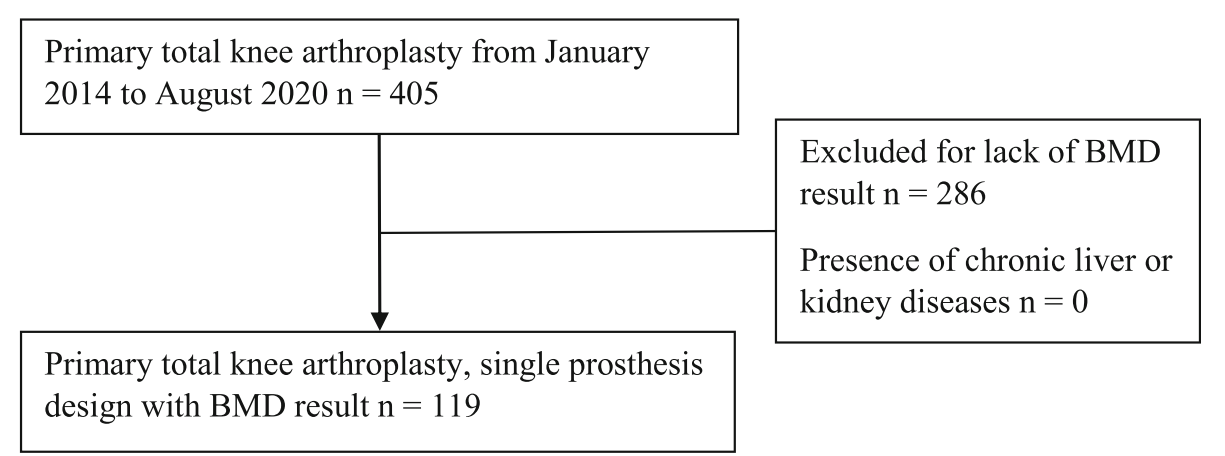

Fig. 1 Flowchart for subject enrollment 
Table 1 Clinical characteristics of the study population categorized by total hip T-score

\begin{tabular}{|c|c|c|c|}
\hline Clinical characteristics & $\begin{array}{l}\text { Normal BMD } \\
(n=69)\end{array}$ & $\begin{array}{l}\text { Low BMD } \\
(n=50)\end{array}$ & $P$ value \\
\hline Age (years) & $72.64 \pm 5.95$ & $73.90 \pm 5.67$ & 0.247 \\
\hline \multicolumn{4}{|l|}{ Sex } \\
\hline Female & $62(89.9 \%)$ & $48(96.0 \%)$ & 0.211 \\
\hline Male & $7(10.1 \%)$ & $2(4.0 \%)$ & \\
\hline BMI $\left(\mathrm{kg} / \mathrm{m}^{2}\right)$ & $27.77 \pm 4.19$ & $25.50 \pm 3.64$ & 0.002 \\
\hline \multicolumn{4}{|l|}{ Anesthesia } \\
\hline Spinal anesthesia & $20(29.0 \%)$ & $16(32.0 \%)$ & 0.724 \\
\hline General anesthesia & 49 (71.0\%) & $34(68.0 \%)$ & \\
\hline \multicolumn{4}{|l|}{ ASA score } \\
\hline 2 & $28(40.6 \%)$ & $14(28.0 \%)$ & 0.156 \\
\hline 3 & $41(59.4 \%)$ & $36(72.0 \%)$ & \\
\hline \multicolumn{4}{|l|}{ Hypertension } \\
\hline Yes & $54(78.3 \%)$ & $43(86.0 \%)$ & 0.283 \\
\hline No & $15(21.7 \%)$ & $7(14.0 \%)$ & \\
\hline \multicolumn{4}{|l|}{ Prior antiplatelet treatment } \\
\hline Yes & $8(11.6 \%)$ & 7 (14.0\%) & 0.696 \\
\hline No & $61(88.4 \%)$ & $43(86.0 \%)$ & \\
\hline Operative time (min) & $103.67 \pm 8.29$ & $96.70 \pm 8.93$ & $<0.001$ \\
\hline \multicolumn{4}{|l|}{ Patella resurfacing } \\
\hline Yes & $59(85.5 \%)$ & $36(72.0 \%)$ & 0.07 \\
\hline No & $10(14.5 \%)$ & $14(28.0 \%)$ & \\
\hline \multicolumn{4}{|l|}{ Blood transfusion } \\
\hline Yes & $2(2.9 \%)$ & $1(2.0 \%)$ & 0.758 \\
\hline No & $67(97.1 \%)$ & 49 (98.0\%) & \\
\hline Postoperative MAP (mmHg) & $96.70 \pm 9.40$ & $95.40 \pm 10.71$ & 0.485 \\
\hline \multicolumn{4}{|l|}{ Laboratory parameters } \\
\hline Hemoglobin $\left(\mathrm{g} / \mathrm{mm}^{3}\right)$ & $12.1 \pm 1.2$ & $12.2 \pm 1.2$ & 0.787 \\
\hline Hematocrit (\%) & $37.3 \pm 3.7$ & $37.4 \pm 3.3$ & 0.884 \\
\hline Platelet $\left(\times 10^{3} / \mathrm{mm}^{3}\right)$ & $261.2 \pm 70.3$ & $246.4 \pm 52.0$ & 0.213 \\
\hline
\end{tabular}

Variables are presented as mean $\pm S D$ or number (count) $B M D$ bone mineral density, $B M I$ body mass index, ASA American Society of Anesthesiologists, MAP mean arterial pressure

Table 2 Comparison between postoperative drainage volume (ml) with BMD site and bone status

\begin{tabular}{llll}
\hline Site & Normal BMD & Low BMD & $P$ value \\
\hline Lumbar spine & $(n=56)$ & $(n=57)$ & 0.836 \\
& $245.0(172.5,330.0)$ & $270.0(190.0,350.0)$ & \\
Trochanter & $(n=58)$ & $(n=61)$ & 0.013 \\
& $282.5(217.5,410.0)$ & $240.0(160.0,320.0)$ & \\
Femoral neck & $(n=22)$ & $(n=97)$ & 0.549 \\
& $260.0(217.5,376.3)$ & $270.0(175.0,340.0)$ & \\
Total hip & $(n=69)$ & $(n=50)$ & 0.003 \\
& $285.0(215.0,410.0)$ & $230.0(150.0,305.0)$ & \\
\hline
\end{tabular}

Variables are presented as medians (the $25^{\text {th }}$ percentile, the $75^{\text {th }}$ percentile) $B M D$ bone mineral density status showed that spinal anesthesia, the operative time, and the total hip BMD status were significantly associated with the postoperative drainage volume $(P=0.022$, 0.014 , and 0.013 , respectively). However, the multivariate regression analysis using the femoral neck BMD status and trochanter BMD status model found that neither femoral neck BMD status nor trochanter BMD status were related to the postoperative drainage volume $(P=$ 0.853 and $P=0.109$, respectively) (Table 4 ).

\section{Discussion}

Postoperative blood loss after TKA is derived from bone and soft tissue, and we could not determine which component generated greater blood loss. Low BMD related to osteoporosis is a common skeletal disorder that is characterized by small bone size and disrupted macroand micro- architectures [27]. This study demonstrated an association between BMD and the postoperative drainage volume following primary TKA. Participants with a normal total hip BMD had a greater postoperative drainage volume than those with a low total hip BMD. The results of this study showed the linkage of bone quality with postoperative blood loss after primary TKA. The vascular supply in the lower extremities was proposed as a reason for this finding, as a low vascular supply may cause a low total hip BMD and low blood loss during surgery. The linkage between the peripheral vascular supply and BMD has been identified by many previous reports [28-31]. Changes in the hip BMD are associated with blood flow to the lower extremities. Decreased BMD at the hip and calcaneus is associated with decreased vascular flow to the lower extremities in healthy, older women [32]. Thus, this low blood supply may cause a low BMD and reduce blood loss post-TKA. However, to determine the exact pathogenesis of this result, further study is required.

Previous studies reported that large blood sinusoids in trabecular bone are commonly found in patients with osteoporosis and lead to increased bleeding during spinal surgery. Patients with low BMD in the spine were found to have greater perioperative blood loss than those with normal BMD in the spine $(357.2 \mathrm{ml}$ vs $259.4 \mathrm{ml})$ during spinal fusion surgery [20]. On the other hand, lumbar spine BMD status was not found to be associated with the postoperative drainage volume following TKA in this study. The local bone architecture and local soft tissue blood supply may be important factors in blood loss. Hip BMD may be correlated more closely with the bone architecture around the knee joints than the spine, so only hip BMD was associated with blood loss after TKA. Moreover, spinal surgery and TKA use different bleeding-control techniques. In this study, a tourniquet was used to reduce the local soft tissue blood supply and may have played an essential role in controlling bleeding. 

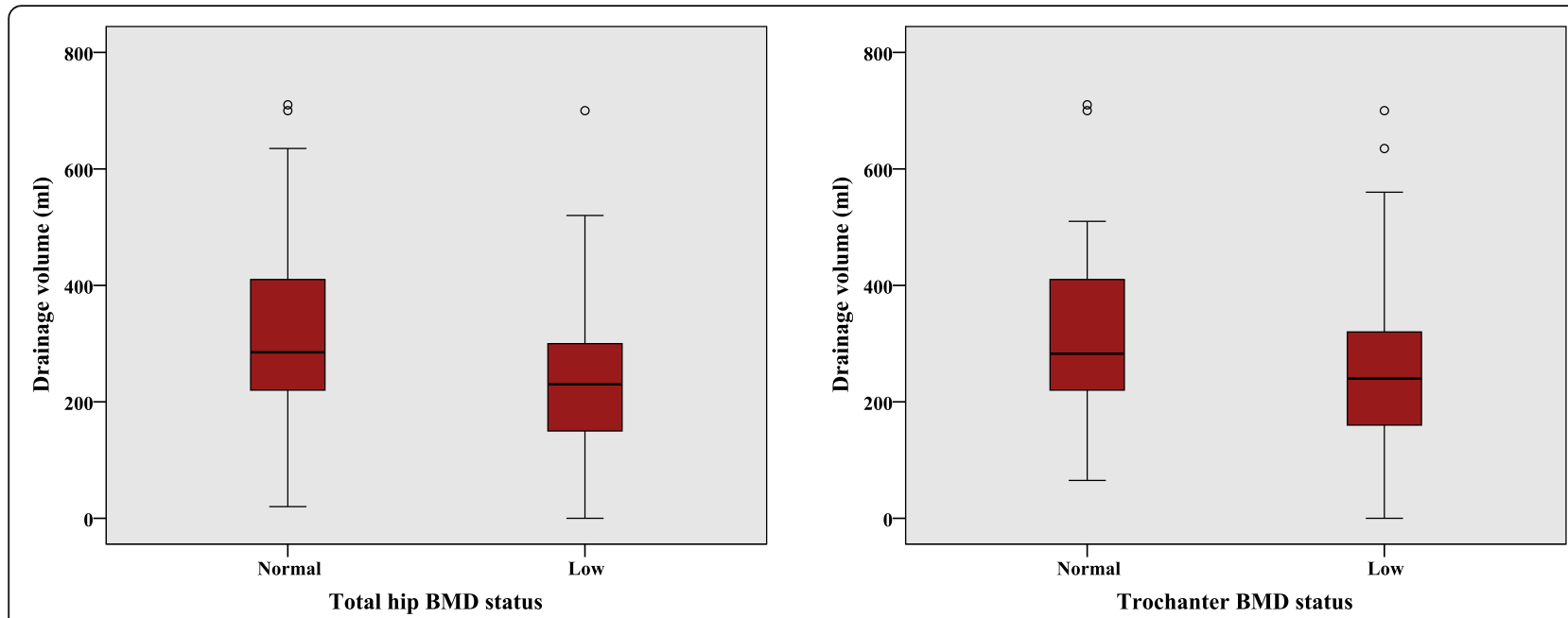

Fig. 2 Box plots of 24-h postoperative drainage volume and BMD status. Outliers are indicated by circles

In addition, the use of a tourniquet and covering of the surface of the bone cut with prosthesis were applied in TKA to decrease blood loss during the operation.

Additionally, this study showed that spinal anesthesia and the operating time were predictive factors associated with an increased postoperative drainage volume in primary TKA. A previous study demonstrated an association between blood loss and type of anesthesia [1]. Similarly, this study supported the finding that regional anesthesia is significantly associated with blood loss in primary TKA. Regarding the operative time, a previous study reported that a longer surgery time is associated with a greater blood transfusion requirement [33]. This study also supported the idea that an increased operative time results in a greater postoperative drainage volume.
This study has several limitations. Firstly, there were missing data, such as blood coagulation results and osteoporosis treatment; also, bias could have existed because of the retrospective nature of the study. Moreover, data on the severity of knee osteoarthritis, degree of soft tissue releases, or peripheral vascular disease were not collected, and this could have been a confounding factor. Secondly, BMD was not directly measured from the distal femur and proximal tibia around the knee joint. However, a previous study reported positive correlations among the distal femur BMD, proximal tibia BMD, and central BMD [34]. The distal femur BMD and proximal tibia BMD should be analyzed to determine their correlations with post-TKA blood loss. Thirdly, the 24-h postoperative drainage volume was included in this analysis. Hidden blood loss may yield a greater volume than

Table 3 Univariate regression analysis of the relationships between variables and the postoperative drainage volume

\begin{tabular}{|c|c|c|c|c|}
\hline Variables & $\beta$ (SE) & $t$ & $P$ & $R^{2}$ \\
\hline Age (years) & $0.009(0.213)$ & 0.100 & 0.920 & 0.000 \\
\hline Sex & $0.061(48.631)$ & 0.663 & 0.508 & 0.004 \\
\hline BMI $\left(\mathrm{kg} / \mathrm{m}^{2}\right)$ & $0.054(3.142)$ & 0.581 & 0.562 & 0.003 \\
\hline Hypertension & $-0.012(33.179)$ & -0.224 & 0.823 & 0.000 \\
\hline Anesthesia (SA vs GA) & $0.100(27.905)$ & 1.087 & 0.279 & 0.010 \\
\hline Operative time (min) & $0.305(1.339)$ & 3.465 & 0.001 & 0.093 \\
\hline Postoperative MAP (mmHg) & $-0.102(1.294)$ & -1.109 & 0.270 & 0.010 \\
\hline Hemoglobin $\left(\mathrm{g} / \mathrm{mm}^{3}\right)$ & $-0.047(10.497)$ & -0.505 & 0.614 & 0.002 \\
\hline Platelet $\left(\times 10^{3} / \mathrm{mm}^{3}\right)$ & $0.028(0.204)$ & 0.299 & 0.766 & 0.001 \\
\hline Lumbar spine status (normal vs low) & $-0.027(25.913)$ & -0.287 & 0.775 & 0.001 \\
\hline Femoral neck status (normal vs low) & $-0.032(33.168)$ & -0.350 & 0.727 & 0.001 \\
\hline Trochanter status (normal vs low) & $-0.219(25.150)$ & -2.423 & 0.017 & 0.048 \\
\hline Total hip status (normal vs low) & $-0.277(25.075)$ & -3.124 & 0.002 & 0.077 \\
\hline
\end{tabular}

$S A$ spinal anesthesia, GA general anesthesia 
Table 4 Multivariate regression analysis of the relationships between variables and the postoperative drainage volume

\begin{tabular}{|c|c|c|c|c|}
\hline Variables & B (SE) & $t$ & $P$ & VIF \\
\hline \multicolumn{5}{|c|}{ Total hip status $\left(R^{2}=0.449 ;\right.$ adjusted $\left.R^{2}=0.202\right)$} \\
\hline Anesthesia (SA vs GA) & $0.218(28.317)$ & 2.328 & 0.022 & 1.105 \\
\hline Operative time (min) & $0.269(1.582)$ & 2.514 & 0.014 & 1.447 \\
\hline Lumbar spine status (normal vs low) & $0.103(27.191)$ & 1.030 & 0.306 & 1.254 \\
\hline Total hip status (normal vs low) & $-0.272(29.815)$ & -2.530 & 0.013 & 1.465 \\
\hline \multicolumn{5}{|c|}{ Trochanter status $\left(R^{2}=0.415 ;\right.$ adjusted $\left.R^{2}=0.173\right)$} \\
\hline Anesthesia (SA vs GA) & $0.211(28.960)$ & 2.210 & 0.029 & 1.115 \\
\hline Operative time (min) & $0.311(1.580)$ & 2.914 & 0.004 & 1.392 \\
\hline Lumbar spine status (normal vs low) & $0.052(26.722)$ & 0.534 & 0.595 & 1.169 \\
\hline Trochanter status (normal vs low) & $-0.170(28.697)$ & -1.617 & 0.109 & 1.348 \\
\hline \multicolumn{5}{|c|}{ Femoral neck status $\left(R^{2}=0.389 ;\right.$ adjusted $\left.R^{2}=0.151\right)$} \\
\hline Anesthesia (SA vs GA) & $0.227(29.177)$ & 2.354 & 0.020 & 1.103 \\
\hline Operative time (min) & $0.362(1.561)$ & 3.432 & 0.001 & 1.325 \\
\hline Lumbar spine status (normal vs low) & $0.017(27.473)$ & 0.165 & 0.869 & 1.204 \\
\hline Femoral neck status (normal vs low) & $0.020(37.517)$ & 0.186 & 0.853 & 1.360 \\
\hline
\end{tabular}

All models were adjusted for age, sex, body mass index, hypertension, postoperative mean arterial pressure, hemoglobin, and platelets

VIF variance inflation factor, $S A$ spinal anesthesia, GA general anesthesia

visible blood loss [35]. Hemoglobin level may be another useful value to represent total blood loss. However, postoperative hemoglobin level was not routinely measured in our setting, so we did not use this value in the analysis.

\section{Conclusions}

This study demonstrated the association between normal total hip BMD and an increased postoperative drainage volume after primary TKA. Additionally, the study showed that spinal anesthesia and the operating time were predictive factors associated with an increased postoperative drainage volume. The concern about type of anesthesia and shorter operative time should be emphasized in normal total hip BMD patients to reduce the postoperative drainage volume after TKA.

\section{Abbreviations}

ASA: American Society of Anesthesiologists; BMD: Bone mineral density; BMI: Body mass index; $\beta$ : Standardized coefficient; DXA: Dual-energy X-ray absorptiometry; GA: General anesthesia; MAP: Mean arterial pressure; $R^{2}$ : Percent variance explained by each variable; SA: Spinal anesthesia; SD: Standard deviation; SE: Standard error; $t$ : Corresponding $t$ value; TKA: Total knee arthroplasty; VIF: Variance inflation factor

\section{Acknowledgements}

We acknowledge Apichart Vachiraphan, Director of the Bamrasnaradura Infectious Diseases Institute, Department of Disease Control, Ministry of Public Health, Nonthaburi, Thailand, for administrative support.

\section{Authors' contributions}

YP designed the study, collected the data, and wrote the manuscript. JL analyzed and interpreted the patient data and wrote the manuscript. KR wrote the manuscript. All authors read and approved the final manuscript.
Funding

This research received no external funding.

Availability of data and materials

The datasets used and/or analyzed during the current study are available from the corresponding author on reasonable request.

\section{Declarations}

Ethics approval and consent to participate

The study protocol was approved by the Institutional Review Board of the Bamrasnaradura Infectious Diseases Institute (S059h/63_ExPD) and was conducted in compliance with the ethical principles of the Helsinki Declaration. Informed consent was waived by the Institutional Review Board which approved the study. All methods were carried out in accordance with the International Council on Harmonisation of Technical Requirements for Registration of Pharmaceuticals for Human Use (ICH) guidelines.

Consent for publication

Not applicable.

\section{Competing interests}

The authors declare that they have no competing interests.

Received: 15 April 2021 Accepted: 27 June 2021

Published online: 28 July 2021

\section{References}

1. Zhu M, Chen JY, Tan YR, Yew AK, Chong HC, Chia SL et al (2015) Effects of anesthetic technique on blood loss and complications after simultaneous bilateral total knee arthroplasty. Arch Orthop Trauma Surg 135(4):565-571. https://doi.org/10.1007/s00402-015-2188-8

2. Sizer SC, Cherian JJ, Elmallah RD, Pierce TP, Beaver WB, Mont MA (2015) Predicting blood loss in total knee and hip arthroplasty. Orthop Clin North Am 46(4):445-459. https://doi.org/10.1016/j.ocl.2015.06.002

3. Hu Y, Li Q, Wei BG, Zhang XS, Torsha TT, Xiao J, Shi ZJ (2018) Blood loss of total knee arthroplasty in osteoarthritis: an analysis of influential factors. J Orthop Surg Res 13(1):325. https://doi.org/10.1186/s13018-018-1038-0 
4. Gandhi R, Evans HM, Mahomed SR, Mahomed NN (2013) Tranexamic acid and the reduction of blood loss in total knee and hip arthroplasty: a metaanalysis. BMC Res Notes 6(1):184. https://doi.org/10.1186/1756-0500-6-184

5. Yang ZG, Chen WP, Wu LD (2012) Effectiveness and safety of tranexamic acid in reducing blood loss in total knee arthroplasty: a meta-analysis. J Bone Joint Surg Am 94(13):1153-1159. https://doi.org/10.2106/JBJS.K.00873

6. Wu YG, Zeng Y, Hu QS, Bao XC, Xiong HZ, Shen B (2018) Tranexamic acid plus low-dose epinephrine reduces blood loss in total knee arthroplasty: a systematic review and meta-analysis. Orthop Surg 10(4):287-295. https://doi. org/10.1111/os.12404

7. Zhang H, Chen J, Chen F, Que W (2012) The effect of tranexamic acid on blood loss and use of blood products in total knee arthroplasty: a metaanalysis. Knee Surg Sports Traumatol Arthrosc 20(9):1742-1752. https://doi. org/10.1007/s00167-011-1754-z

8. Hinarejos P, Corrales M, Matamalas A, Bisbe E, Caceres E (2009) Computerassisted surgery can reduce blood loss after total knee arthroplasty. Knee Surg Sports Traumatol Arthrosc 17(4):356-360. https://doi.org/10.1007/s001 67-008-0683-y

9. Han SB, Kim HJ, Kim TK, In Y, Oh KJ, Koh IJ et al (2016) Computer navigation is effective in reducing blood loss but has no effect on transfusion requirement following primary total knee arthroplasty: a meta-analysis. Knee Surg Sports Traumatol Arthrosc 24(11):3474-3481. https://doi.org/10.1007/ s00167-016-4053-x

10. Licini DJ, Meneghini RM (2015) Modern abbreviated computer navigation of the femur reduces blood loss in total knee arthroplasty. J Arthroplast 30(10): 1729-1732. https://doi.org/10.1016/j.arth.2015.04.020

11. Tsumara N, Yoshiya S, Chin T, Shiba R, Kohso K, Doita M (2006) A prospective comparison of clamping the drain or post-operative salvage of blood in reducing blood loss after total knee arthroplasty. J Bone Joint Surg Br. 88(1):49-53

12. Banerjee S, Kapadia BH, Issa K, McElroy MJ, Khanuja HS, Harwin SF, Mont M (2013) Postoperative blood loss prevention in total knee arthroplasty. J Knee Surg. 26(6):395-400. https://doi.org/10.1055/s-0033-1357491

13. Wang CG, Sun ZH, Liu J, Cao JG, Li ZJ (2015) Safety and efficacy of intraarticular tranexamic acid injection without drainage on blood loss in total knee arthroplasty: a randomized clinical trial. Int J Surg 20:1-7. https://doi. org/10.1016/j.jjsu.2015.05.045

14. Li ZJ, Fu X, Tian P, Liu WX, Li YM, Zheng YF, Ma XL, Deng WM (2015) Fibrin sealant before wound closure in total knee arthroplasty reduced blood loss: a meta-analysis. Knee Surg Sports Traumatol Arthrosc 23(7):2019-2025. https://doi.org/10.1007/s00167-014-2898-4

15. Wang K, Yuan W, An J, Cheng P, Song P, Li S, et al. Sealing the Intramedullary Femoral Canal for Blood Loss in Total Knee Arthroplasty: A Meta-analysis of Randomized Controlled Trials. J Knee Surg. 2021;34(2):20815. https://doi.org/10.1055/s-0039-1694025.

16. Wu Y, Yang T, Zeng Y, Si H, Li C, Shen B (2017) Effect of different postoperative limb positions on blood loss and range of motion in total knee arthroplasty: an updated meta-analysis of randomized controlled trials. Int J Surg 37:15-23. https://doi.org/10.1016/i.jisu.2016.11.135

17. Bernatz JT, Krueger DC, Squire MW, Illgen RL 2nd, Binkley NC, Anderson PA (2019) Unrecognized osteoporosis is common in patients with a wellfunctioning total knee arthroplasty. J Arthroplast 34(10):2347-2350. https:// doi.org/10.1016/j.arth.2019.05.041

18. Ha CW, Park YB (2020) Underestimation and undertreatment of osteoporosis in patients awaiting primary total knee arthroplasty. Arch Orthop Trauma Surg 140(8):1109-1114. https://doi.org/10.1007/s00402-02003462-y

19. Andersen MR, Winther NS, Lind T, Schroder HM, Flivik G, Petersen MM (2017) Low preoperative BMD is related to high migration of tibia components in uncemented TKA-92 patients in a combined DEXA and RSA study with 2-year follow-up. J Arthroplast 32(7):2141-2146. https://doi.org/1 0.1016/j.arth.2017.02.032

20. He Y, Liu C, Huang Y (2020) Can bone mineral density affect intra-operative blood loss of mini-invasive posterior lumbar interbody fusion? Endosc Robot Surg 3(3):66-69

21. Xue AL, Wu SY, Jiang L, Feng AM, Guo HF, Zhao P (2017) Bone fracture risk in patients with rheumatoid arthritis: a meta-analysis. Medicine (Baltimore) 96(36):e6983. https://doi.org/10.1097/MD.0000000000006983

22. Prasad N, Padmanabhan V, Mullaji A (2007) Blood loss in total knee arthroplasty: an analysis of risk factors. Int Orthop 31(1):39-44. https://doi. org/10.1007/s00264-006-0096-9
23. Magill P, Cunningham EL, Hill JC, Beverland DE (2018) Identifying the period of greatest blood loss after lower limb arthroplasty. Arthroplasty Today 4(4): 499-504. https://doi.org/10.1016/j.artd.2018.09.002

24. Pookarnjanamorakot C, Sirisriro R, Eurvilaichit C, Jaovisidha S, Koysombatolan I (2004) The incidence of deep vein thrombosis and pulmonary embolism after total knee arthroplasty: the screening study by radionuclide venography. J Med Assoc Thail 87(8):869-876

25. Faul F, Erdfelder E, Lang AG, Buchner A (2007) G*Power 3: a flexible statistical power analysis program for the social, behavioral, and biomedical sciences. Behav Res Methods 39(2):175-191. https://doi.org/10.3758/BF031 93146

26. Mickey RM, Greenland S (1989) The impact of confounder selection criteria on effect estimation. Am J Epidemiol 129(1):125-137. https://doi.org/10.1 093/oxfordjournals.aje.a115101

27. Choksi P, Jepsen KJ, Clines GA (2018) The challenges of diagnosing osteoporosis and the limitations of currently available tools. Clin Diabetes Endocrinol 4(1):12. https://doi.org/10.1186/s40842-018-0062-7

28. Mangiafico RA, Russo E, Riccobene S, Pennisi P, Mangiafico M, D'Amico F, Fiore CE (2006) Increased prevalence of peripheral arterial disease in osteoporotic postmenopausal women. J Bone Miner Metab 24(2):125-131. https://doi.org/10.1007/s00774-005-0658-8

29. von Muhlen D, Allison M, Jassal SK, Barrett-Connor E (2009) Peripheral arterial disease and osteoporosis in older adults: the Rancho Bernardo Study. Osteoporos Int 20(12):2071-2078. https://doi.org/10.1007/s00198-0090912-3

30. Collins TC, Ewing SK, Diem SJ, Taylor BC, Orwoll ES, Cummings SR, Strotmeyer ES, Ensrud KE, Osteoporotic Fractures in Men (MrOS) Study Group (2009) Peripheral arterial disease is associated with higher rates of hip bone loss and increased fracture risk in older men. Circulation. 119(17): 2305-2312. https://doi.org/10.1161/CIRCULATIONAHA.108.820993

31. Tanko LB, Bagger YZ, Christiansen C (2003) Low bone mineral density in the hip as a marker of advanced atherosclerosis in elderly women. Calcif Tissue Int 73(1):15-20. https://doi.org/10.1007/s00223-002-2070-x

32. Vogt MT, Cauley JA, Kuller LH, Nevitt MC (1997) Bone mineral density and blood flow to the lower extremities: the study of osteoporotic fractures. J Bone Miner Res 12(2):283-289. https://doi.org/10.1359/jbmr.1997.12.2.283

33. Noticewala MS, Nyce JD, Wang W, Geller JA, Macaulay W (2012) Predicting need for allogeneic transfusion after total knee arthroplasty. J Arthroplast 27(6):961-967. https://doi.org/10.1016/j.arth.2011.10.008

34. Beattie KA, Boulos P, Duryea J, O'Neill J, Pui M, Gordon CL, Webber CE, Adachi JD (2005) The relationships between bone mineral density in the spine, hip, distal femur and proximal tibia and medial minimum joint space width in the knees of healthy females. Osteoarthr Cartil 13(10):872-878. https://doi.org/10.1016/j.joca.2005.06.010

35. Sehat KR, Evans RL, Newman JH (2004) Hidden blood loss following hip and knee arthroplasty. Correct management of blood loss should take hidden loss into account. J Bone Joint Surg Br 86(4):561-565

\section{Publisher's Note}

Springer Nature remains neutral with regard to jurisdictional claims in published maps and institutional affiliations.

Ready to submit your research? Choose BMC and benefit from:

- fast, convenient online submission

- thorough peer review by experienced researchers in your field

- rapid publication on acceptance

- support for research data, including large and complex data types

- gold Open Access which fosters wider collaboration and increased citations

- maximum visibility for your research: over $100 \mathrm{M}$ website views per year

At $\mathrm{BMC}$, research is always in progress.

Learn more biomedcentral.com/submission 